\title{
Australian corals thriving out of water in an extreme environment
}

Received: 31 August 2010/ Accepted: 8 October 2010/Published online: 3 November 2010

(C) Springer-Verlag 2010

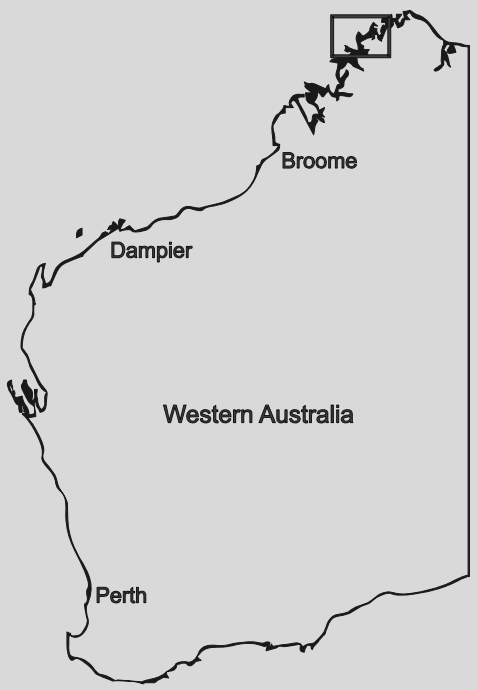

Fig. 1 Map of Western Australia showing the location of the Bonaparte Archipelago (box)
The Bonaparte Archipelago is a group of islands located off the northwest coast of Australia, in the little-known region of the Kimberley (Fig. 1), which has unusual coral reefs. The Archipelago is characterized by small islands with fringing coral reefs of high diversity, strong currents and high turbidity. Mean monthly sea surface temperature (SST) ranges from $26.5^{\circ} \mathrm{C}$ in August to $31.4^{\circ} \mathrm{C}$ in December, with the mean monthly SST above $30.0^{\circ} \mathrm{C}$ for five months of the year (sourced from Remote Sensing Systems satellites sponsored by NASA http://www.remss.com/). Tides are extreme, with tidal amplitudes of up to $10 \mathrm{~m}$ during spring tides. Extreme spring tides occur twice annually around the autumn and spring equinoxes, when subtidal coral communities are exposed (Fig. 2a) for periods of up to one hour, and intertidal coral communities are exposed for periods of up to three hours. Fringing coral reefs extend over several kilometers on some islands, and prolonged aerial exposure is within the tolerance limits of a wide range of corals in this habitat (Fig. 2b).

Acknowledgments INPEX Browse, Total EP Australia and RPS Environment provided field and logistical support. Barry Wilson provided photograph Fig. 2a.
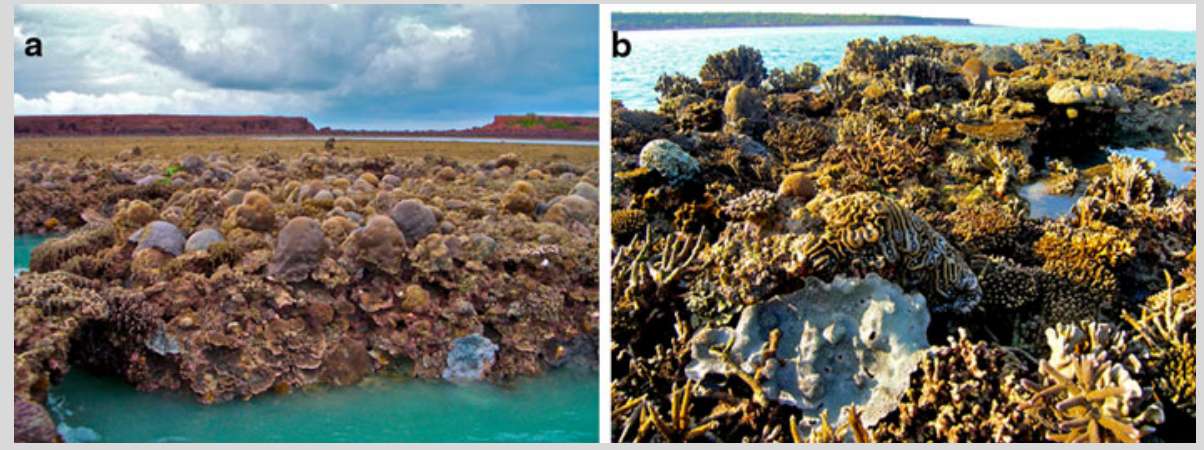

Fig. 2 Coral assemblages in the Bonaparte Archipelago (a) a subtidal reef exposed on a spring low tide (b) the high diversity of the exposed reefs in the Archipelago

N. L. Rosser $(\bowtie)$

RPS Environment, 38 Station St, Subiaco, WA 6008, Australia

e-mail: rossen01@student.uwa.edu.au

\section{J. E. N. Veron}

Coral Reef Research, 10 Benalla Rd, Townsville, QLD 4811, Australia

e-mail: j.veron@coralreefresearch.com

Present Address:

N. L. Rosser

School of Animal Biology, University of Western Australia, Crawley, WA 6009, Australia

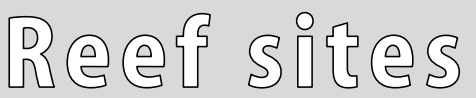

Coral Reefs (2011) 30:21

DOI $10.1007 / \mathrm{s} 00338-010-0689-\mathrm{z}$ 